http://www.doi.org/10.14718/ACP.2021.24.1.1

Editorial

\title{
La espera y la esperanza en la ciencia
}

\author{
Iván Felipe Medina Arboleda*
}

Al momento en que escribo esta editorial, el mundo se prepara para varios de los desafíos logísticos, sanitarios y sociales más importantes de los últimos cincuenta años, como lo son la distribución de las diferentes vacunas contra la COVID-19, la reactivación económica de interconexión mundial y los impactos poblacionales en todos los ámbitos derivados del último año de medidas restrictivas. Ahora, si bien aún es pronto para evaluaciones a gran escala de las transformaciones y repercusiones de estos desafíos, hay algunas anotaciones preliminares ante la crisis sanitaria en la región y sus implicaciones para la psicología.

En primer lugar, debemos destacar el tesón de las personas que han hecho del cuidado de la salud su profesión: los enfermeros, médicos, asistentes, psicólogos, auxiliares, etc., protagonistas de una abnegación estoica incluso cuando no hemos estado a la altura de su entrega. A su vez, a quienes las medidas de confinamiento llevaron a la exposición directa y que han sufrido en América Latina los embates mayoritarios de la mortalidad: los trabajadores y trabajadoras de los sectores que nunca se detuvieron, o para quienes detener sus actividades no ha sido una opción. Sabemos que la mortalidad del virus en Latinoamérica ha estado asociada a la compleja relación de las condiciones de salud y la condición social, en donde, a menores ingresos y presencia de condiciones laborales informales, mayores condiciones comórbidas y gravedad de las afectaciones del virus.

En segundo lugar, sabemos que hay que enfrentar las implicaciones de las medidas de confinamiento actuales $\mathrm{y}$ venideras. Como hemos visto, la incertidumbre laboral aumentó los tiempos de las jornadas laborales y deterioró las condiciones de vida digna en el espacio privado en gran parte de la población, obligada a convivir con el quehacer profesional, el teletrabajo, la enseñanza remota y la convivencia dentro de sus residencias; condiciones, de por sí insólitas y abrumadoras, que son aún más desafiantes para quienes la conectividad digital es de baja calidad e incluso así persistieron en continuar vinculados en la sincronicidad digital.
Renglón aparte merece el sector educativo que emplea a la mayoría de los investigadores en psicología de la región, pues la formación se mantuvo a flote sobre la buena voluntad de los estudiantes y la entereza de quienes afrontaron este reto, sea como profesores o como personal de soporte de tal actividad.

En este contexto, vimos cómo en la edición científica, que se debe a los revisores internos y externos de las publicaciones, estos investigadores y profesores universitarios - aquellos garantes de la exigencia y el rigor académicos-, en estos tiempos de extrajornadas, dobles jornadas encubiertas - sobre todo para las mujeres - y condiciones de evaluaciones nacionales e institucionales, nunca se detuvieron; por el contrario, dedicaron sus horas en estas complicadas condiciones a que las revistas continuaran funcionando.

Pero en ningún caso se trata de un agradecimiento dedicado solo a quienes evaluaron, pues este cubre también a quienes declinaron de hacerlo —opción siempre válida y, en estas circunstancias, más que justa—. Este reconocimiento es una necesaria puesta en público de las condiciones que enfrenta la edición académica de la región y que se refleja en las demoras sistemáticas de todas las fases, las cuales, además, por fuera de las voluntades de los equipos de las publicaciones, nos muestran cuán interconectados y vulnerables estamos como actores de la sociedad del conocimiento.

En los diferentes sectores, incluido el editorial, a pesar de las dificultades de la pandemia, esperamos, continuamos y ahora aguardamos por los frutos del descomunal esfuerzo del año 2020. Y tal es el caso de este volumen 24 número 1 de la revista Acta Colombiana de Psicología, pues acá presentamos el resultado de una coordinación sin parangón reciente para la comunidad académica en términos de las excepcionalidades que rodearon el proceso editorial.

Si miramos atrás, vale la pena preguntarse cómo nuestras sociedades y comunidades siguieron adelante y no declinaron para alcanzar estas pequeñas grandes cumbres. Sabemos, por la investigación, que la esperanza nos mantiene en pie,

Editor general. Acta Colombiana de Psicología. revistaacta@ucatolica.edu.co; https://orcid.org/0000-0003-3209-9204 
y esa esperanza, entre otras, en la ciencia, dio y continúa dándonos razones para encarar el porvenir.

La promesa cumplida por la bioquímica es una confirmación de que la espera y la esperanza valieron la pena. Sin embargo, no es el único campo llamado a aportar en esta época de esperanzas en la ciencia. Las transformaciones sociales, positivas y negativas, presentes y venideras, han desafiado los límites disciplinares de la psicología en sus diferentes especialidades: las sociedades esperan y tienen su esperanza puesta en la comunidad científica de nuestra disciplina, y es un momento histórico para no defraudar tales expectativas. 